\title{
Use of Demolished Recycled Aggregate for Pavement Construction: A Review
}

\author{
Dikshant Sharma, Prachi Kushwaha, Nishant Sachdeva \\ Department of Civil Engineering, Swami Keshvanand Institute of Technology, Management \& Gramothan, Jaipur- \\ 302017 (INDIA) \\ Email: sharmadikshant4@gmail.com,prachi.kushwaha@skit.ac.in, nishant.sachdeva@skit.ac.in \\ Received 7.08.2021, received in revised form 25.08.2021, accepted 28.08.2021 \\ doi: $\underline{10.47904 / I J S K I T .11 .2 .2021 .22-26 ~}$
}

\begin{abstract}
In today's scenario, availability of natural aggregates is diminishing and simultaneously the waste generation due to debris of demolished buildings is increasing considerably. Incorporationg these demolished materials into construction process can provide a respite from both these issues. The aggregate from demolished structures mainly consists of 70-80\% of concrete components as per different studies, so it will be very beneficial for the environment to recycle this aggregate for construction works. In this paper a review of contemporary practices of use of recycled concrete aggregate in pavement construction has been done.
\end{abstract}

Keywords- construction wastes, RAC, sustainable planning, pavement

\section{INTRODUCTION}

To meet the need of the present and retain the natural resources for the future generations to fulfill their own needs is known as sustainable development. The goals of economic and social development in developing and developed countries must be defined in terms of sustainability [1]. Solid waste consists of a large proportion of Construction and Demolition (C\&D) waste. Effective management of C\&D waste is essential for promoting and achieveing the goal of sustainable development [2]. C\&D waste accounts for $25 \%$ of the total waste generated around the globe and this is a serious issue to be looked upon [3]. Out of all the construction and demolition waste generated it is reported that almost $75 \%$ is concrete waste [4].

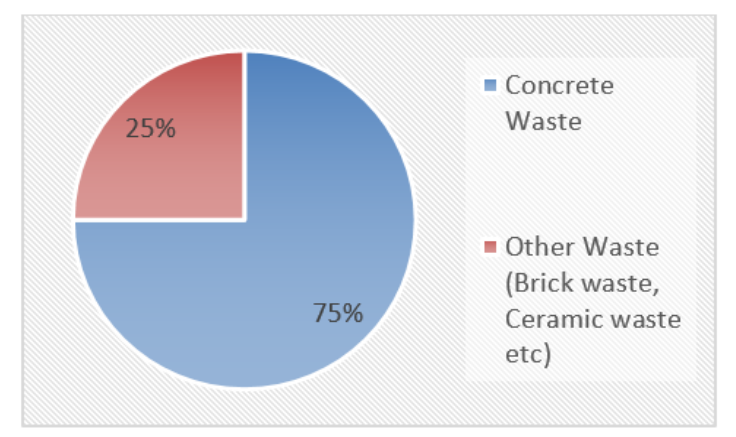

Fig. 1 Percentage of Concrete Waste in Total C\&D Waste Generated [4]

Concrete is a composite material which is one of the major portions of $C \& D$ waste. Concrete consists of aggregate, water, cement and admixtures. Among all these materials, $65 \%-70 \%$ of the total volume of concrete is occupied by aggregates [5]. Approximately 20 billion metric tons of coarse aggregates are used every year in concrete production [6]. The demand is for the same is expected to increase by $100 \%$ in next few decades. India being a developing nation has ensured its position in the top ten consumers of these natural resources [7]. The importance of reducing the huge quantity of $C \& D$ waste is a priority for the researchers. Their use in construction industry is one of alternative to keep the environment clean [8].

Recycling comprises of the process the used material to be used in making a brand-new product. The use of a natural combination of aggregate is obtaining a lot of intense with the recent growth in infrastructure space. Recycled concrete aggregates (RCA) combination mix constitutes of material processed from construction and demolition junk that is crushed and graded to confirm to the required size. After the reprocessing of this mineral waste material the aggregates generated comprises of $C \& D$ waste majorly. These wastes area unit unremarkably comprises of junk of concrete sometimes constitutes the most important proportion of $C \& D$ waste. In different studies it has been pointed out that after separating and sieving crushed concrete waste from the composit C\&D waste, it can be successfully utilized as a replacement of natural coarse aggregate in various layers of pavement such as sub-base and base layers. Recycled Concrete aggregate (RCA) as an alternative to NCA from mines and natural sources is a solution that could probably address these economic and environmental considerations.

\section{SCOPE OF THE STUDY}

This study focusses on the performance of aggregates obtained from C\&D waste in concrete to be used for rigid pavement construction. An organized literature study was done. Relevant literature was found using keyword-based search. Maximum data-base was taken from Google Scholar (www.scholar.google.com). Attempt has been made to select latest research papers (After 2010) but few relevant older research papers are also included. Emphasis is given to the effects on strength and durability properties of concrete after the addition of RAC. The results are also presented in tabular form 
for easy understanding. At the end, final conclusions are drafted.

\section{EFFECT OF INCLUSION OF RAC IN PAVEMENT LAYERS}

Researchers in the past have evaluated the prospective use of RCA in pavement bases, subbases, asphalt and concrete mixes [9, 10, 11]. It is imperative to establish the functional performance of the mix in laboratory as well as field as the performance of the structure will be influenced by the quality of raw material used in construction [12]. For use in pavement layers the properties of recycled aggregates shall be homogeneous and shall satisfy the necessary standards [13].

Rahman et. al., [14], analysed the variation in compressive strength of mix on inclusion of various sizes of RCA. It was concluded that $10 \mathrm{~mm}$ and 14 $\mathrm{mm}$ size of recycled aggregate in concrete mixes exhibited properties similar to those of natural aggregate. In another study by Parekh and Modhera [15], properties of natural aggregates were compared against those of recycled aggregates in different proportions as per different standards followed in various countries. Safiuddina et. al., [16], in their study explored the consequences of RCA on both; the fresh and the hardened properties of concrete. They concluded that inclusion of RCA reduces the workability and also affects the amount of permeable voids and compressive strength of the mix. This study established that after 28 days of curing a mix consisting of $100 \%$ RCA; compressive strength achieved was $12.2 \%$ lower than that of a mix made of virgin natural aggregates.

A. Arulrajah, J. Piratheepan [17], carried out a study investigating the geotechnical properties of recycled concrete aggregate (RCA). They found the CBR values to be satisfactory as per the local authorities' guidelines for use of RCA in sub-bases. Sonawane and Pimplikar [18], carried out a laboratory investigation using recycled concrete aggregate and concluded that upto $30 \%$ inclusion of RCA does not affect the functional requirements of the structure. Reddy and Kumar [19], presented an overview of use of recycled concrete aggregates as a sustainable construction alternative. The influence of manufacturing process and processing techniques on various characteristics of aggregates and thereby the various concrete properties associated with nonstructural applications were studied and it was concluded that control over source concrete is essential. They established that laboratory produced concrete has a slight advantage in terms of performance but its permeability is low.

Husain and Assas [20] conducted a study on utilization of demolished concrete by replacing fresh aggregates with recycled aggregates in varying percentages. Test results of compressive strength test depict that in both i.e. partial replacement and complete replacement the compressive strength values were higher compared to those of concrete with virgin aggregates. Jindal et. al., [21] from their study concluded that the mortar stuck to the surface of recycled aggregates increases the porosity of recycled aggregates and a proper method should be adopted for removal of the same. They also stated that different use of recycled aggregate concrete does not vary the strength of the concrete much; however, to avoid the loss in strength and other properties some inert material should be incorporated. A number of studies have stressed upon the need of establishing unified specifications for the use of recycled concrete aggregate in pavements for making the application easier [21,22].

Kalpavalli and Naik [23] from their study established that the results of split tensile strength, flexural strength and compressive strength indictae that RCA exhibited lower strength than the NCA mixes but it is still within the specified range and can be used for the structural purpose. They also concluded that due to presence of attached mortar the recycled aggregate exhibit higher water absorption in contrast to natural aggregates. Vishal V Panchal et. al. [24], studied about the feasibility of Construction Demolition Waste (CDW) for performance enhancement of subgrade and sub-base layer in the road design. They conducted standard tests and analysed the results for the application of CDW to bring about performance improvement of subgrade and sub base layer in the highway construction and design process. The results of normal aggregate and construction demolition aggregate were compared to study the effect on the property of road pavement in which it was found that Marshall Stability of conventional aggregate was found to be $10.15 \mathrm{KN}$, Average Flow of the conventional aggregate was found to be 3.29 $\mathrm{mm}$, Marshall Stability of CDW aggregate was found to be $9.10 \mathrm{KN}$, Average Flow of CDW aggregate was found to be $2.96 \mathrm{~mm}$

Amani et. al., [25] based their study on M 25 recycled aggregate concrete with addition of silica upto $2 \%$. They utilized Nano silica to improve the compressive strength of concrete. The strength properties at 7 days, 28 days and 56 days were observed. From the results it was concluded that the slump value of RAC with and with out mixing of nanosilica is less than the mix containing natural aggregates. They advocated that to achieve strength equivalent to mixes made with natural aggregates Nano-sillica shall be used in mixes obtained by replacing virgin aggregates with recycled aggregates. 
Table 1 Summary of prominent reviewed research for use of Recycled Concrete Aggregates (RAC) in concrete

\begin{tabular}{|c|c|c|c|c|}
\hline S. No & $\begin{array}{c}\text { Year of } \\
\text { Publication }\end{array}$ & Evaluated Parameters & Optimum Content/Conclusion Drawn & Ref. \\
\hline 1 & 2012 & $\begin{array}{l}\text { Marshall stability, indirect } \\
\text { tensile resilient modulus, } \\
\text { dynamic creep and indirect } \\
\text { tensile fatigue tests }\end{array}$ & $\begin{array}{l}\text { - Best results these tests were observed when RCA was used } \\
\text { along with steel slag. }\end{array}$ & [4] \\
\hline 2 & 2016 & $\begin{array}{l}\text { Impact value, crushing value, } \\
\text { abrasion value. XRD and SEM } \\
\text { analysis }\end{array}$ & $\begin{array}{l}\text { - Presoaking of aggregates in acids improves the properties } \\
\text { of RAC and this method can be used for large scale } \\
\text { projects. }\end{array}$ & {$[10]$} \\
\hline 3 & 2013 & $\begin{array}{l}\text { Marshall Stability, stiffness, } \\
\text { permanent deformation and } \\
\text { fatigue }\end{array}$ & $\begin{array}{l}\text { - } 20 \%-30 \% \text { RCA can be used in asphalt mixes. } \\
\text { - Further investigations are required to determine exact } \\
\text { percenrage replacement of RAC. }\end{array}$ & [11] \\
\hline 4 & 2009 & Compressive strength & $\begin{array}{l}\text { - Compressive strength of size } 10 \mathrm{~mm} \text { and } 14 \mathrm{~mm} \text { RAC was } \\
\text { similar to that of NAC. } \\
\text { - } 20 \mathrm{~mm} \text { size RAC showed less strength to that of NAC. }\end{array}$ & [14] \\
\hline 5 & 2011 & Slump and slump flow & $\begin{array}{l}\text { - Maximum decrease in compressive strength was } 12.2 \% \\
\text { for } 100 \% \text { RAC replacement. } \\
\text { - Flexural strength and splitting tensile strength were not } \\
\text { affected by replacement. } \\
\text { - Modulus of elasticity decreased and permeable voids } \\
\text { increased on increasing RAC content. }\end{array}$ & [16] \\
\hline 6 & 2013 & $\begin{array}{l}\text { Compressive strength, flexural } \\
\text { strength, workability }\end{array}$ & $\begin{array}{l}\text { - upto } 30 \% \text { use of RCA does not affect the functional } \\
\text { requirements }\end{array}$ & {$[18]$} \\
\hline 7 & 2013 & $\begin{array}{c}\text { Water absorption, sieve } \\
\text { analysis, crushing value, } \\
\text { impact value, los angeles } \\
\text { bbrasion value, workability }\end{array}$ & $\begin{array}{l}\text { - Water absorption, Impact, crushing and los angeles } \\
\text { abrasion value increases on increasing the RAC content. } \\
\text { - Compressive strength increases when } 75 \% \text { fresh } \\
\text { aggregates were replaced by RAC. } \\
\text { - High increase in slump value on increasing RAC content. }\end{array}$ & {$[20]$} \\
\hline 8 & 2015 & $\begin{array}{l}\text { Compressive, flexural strength } \\
\text { and split tensile strength }\end{array}$ & $\begin{array}{l}\text { - Compaction factor value reduces on increasing } \\
\text { replacement percentage. } \\
\text { - Strength of recycled aggregates takes more curing duration } \\
\text { to achieve higher strength. } \\
\text { - Split tensile strength and flexural strength results were } \\
\text { reduced on replacement but were within specified limits. } \\
\text { - } 30 \% \text { of fresh aggregates can be replaced. }\end{array}$ & [23] \\
\hline 9 & 2018 & $\begin{array}{l}\text { Compressive strength, split } \\
\text { tensile strength, NDT (rebound } \\
\text { hammer and UPV) }\end{array}$ & $\begin{array}{l}\text { Addition of nano silica (NS) with RAC reduces the } \\
\text { reduction in compressive strength from } 4.78 \% \text { to } 1.87 \% \text {. } \\
\text { - } \text { Addition of NS with RAC increases split tensile strength } \\
\text { by } 9.2 \% \text {. } \\
\text { - Similar improvement in flexural strength was also seen on } \\
\text { addition of NS. } \\
\text { - } 30 \% \text { RAC along with NS can be used. }\end{array}$ & [25] \\
\hline 10 & 2019 & $\begin{array}{l}\text { Flexural strength, compressive } \\
\text { strength }\end{array}$ & $\begin{array}{l}\text { - With use of magnesium sulphate 5\% solution compressive } \\
\text { strength and flexural Strength has been reduced. }\end{array}$ & [26] \\
\hline 11 & 2020 & $\begin{array}{l}\text { Compressive strength, flexural } \\
\text { strength, split tensile strength, } \\
\text { non destructive testing, acid } \\
\text { tests, ater absorption }\end{array}$ & $\begin{array}{l}\text { - All the parameters reduced on addition of washed RAP or } \\
\text { dirty RAP. } \\
\text { - At } 20 \% \text { replacement, values reduced but remained in the } \\
\text { limits prescribed by IS standards. } \\
\text { - Optimum content of } 20 \% \text { replacement and } 21 \text { days curing } \\
\text { was determined. }\end{array}$ & {$[28]$} \\
\hline
\end{tabular}

Busari et. al., [26] carried out a review of existing literature and analysed the state of generation, characterization and utilization of construction and demolition waste in pavement construction. They evaluated the various benefits associated with use of recycled aggregates in terms of economic, social and environmental benefits. They stated that variables such as construction material quality, scale of the project, contract, mode of construction incorporated shall lay an effect on the the amount and quality of construction/demolition waste generated. Mroueh et al. [27] studied the use of different by products of industrial production in the process of construction of pavements. Life cycle assessment was also conducted for all these by products. They stated that to curb the environmental imooact of use of natural materials, pavement construction using RCA could prove to be an asset. Out of all the industrial by products incorporated for the study a roadbase of RCA was established to have achieved a sizable environmental benefit over others as it emittied least GHG gases and consumed lowest energy. Singh Manpreet et. al. [28] used washed RAC in place of natural aggregates in DLC. In this study, results of washed RAP was compared with dirty RAP. It was resulted from SEM analysis that the formation of 
CSH gel which is mainly responsible for pozzolanic properties reduced on addition of dirty RAP due to presence of dust particles. Optimum percentage replacement of washed RAP was determined as 20 $\%$ with 21 days curing.

The recommendations as per various sources advocate use of 15 to $100 \%$ of RCA inc pavements. The inconsistency in the available guidelines for incorporation of RCA for gainful utilization can be observed in the available literature about the topic. This discrepancy gives rise to subsequent uncertainity in field applications [29].

Application of Recycled Aggregates:

- It helps to initiate a plan of sustainable development for the preservation of nature and the environmental benefits and will decrease the dumping of concrete waste from old construction site.

- Recycled aggregate could also be used for various application in road making such as pavement, shoulder, median barrier, sidewalk, curb foundation of building and bridge.

- Recycled concrete aggregate can be used in layers of road in sub bases and support layers such as sub base and also inWBM roads.

- The cost of recycle aggregate is less as ompared to natural aggregate which led to more economical construction.

\section{CONCLUSION}

Following conclusions can be drawn from the available literature -

- From previous studies it is clear that RCA in careful proportions can be used with natural aggregate without any strength loss.

- Excessive proportion mix of Recycled aggregate resulted in loss of characteristic strength of the concrete.

- Studies have established that incorporation of RCA in construction work counters the harmful effects of Construction and demolition waste on ecology and surroundings

- Standardization of procedure to be followed for utilization of recycled concrete aggregates shall be done to make the research results more inclusive.

- Advanced research work is needed in the field of recycled aggregate field to compete with the modern demands.

\section{REFERENCES}

[1] Bruntland, G. H. (1987). Report of the World Commission on environment and development; our common future, Bruntland report. New York: UN Documents.

[2] Wu, Z., Yu, A. T., \& Poon, C. S. (2020). Promoting effective construction and demolition waste management towards sustainable development: A case study of Hong Kong. Sustainable Development, 28(6), 1713-1724.

[3] Alsheyab, M. A. T. (2021). Recycling of construction and demolition waste and its impact on climate change and sustainable development. International Journal of Environmental Science and Technology, 1-10.

[4] Arabani, M., \& Azarhoosh, A. R. (2012). The effect of recycled concrete aggregate and steel slag on the dynamic properties of asphalt mixtures. Construction and Building Materials, 35, 1-7.

[5] Kosmatka, S. H., Panarese, W. C., \& Kerkhoff, B. (2002). Design and control of concrete mixtures (Vol. 5420, pp. 60077-1083). Skokie, IL: Portland Cement Association.

[6] Mehta, P. K., \& Meryman, H. (2009). Tools for reducing carbon emissions due to cement consumption. Structure, 1(1), 11-15.

[7] ] Oikonomou ND. Recycled concrete aggregates. Cem Concr Compos 2005;27:315-8.

[8] Barbuta, M., Bucur, R. D., Cimpeanu, S. M., Paraschiv, G., \& Bucur, D. (2015). Wastes in building materials industry. Agroecology, 1(1), 81-99.

[9] Arulrajah, A., Piratheepan, J., \& Disfani, M. M. (2014). Reclaimed asphalt pavement and recycled concrete aggregate blends in pavement subbases: laboratory and field evaluation. Journal of Materials in Civil Engineering, 26(2), 349-357.

[10] Saravanakumar, P., Abhiram, K., \& Manoj, B. (2016). Properties of treated recycled aggregates and its influence on concrete strength characteristics. Construction and Building Materials, 111, 611-617.

[11] Pasandín, A. R., \& Pérez, I. (2013). Laboratory evaluation of hot-mix asphalt containing construction and demolition waste. Construction and Building Materials, 43, 497-505.

[12] Bocci, E., Cerni, G., \& Colagrande, S. (2016). Mechanical behaviour of asphalt concrete containing C\&D recycled materials. In 8th RILEM International Symposium on Testing and Characterization of Sustainable and Innovative Bituminous Materials (pp. 557-568). Springer, Dordrecht.

[13] Tam, V. W., Soomro, M., \& Evangelista, A. C. J. (2018). A review of recycled aggregate in concrete applications (2000-2017). Construction and Building Materials, 172, 272-292.

[14] Rahman, I. A., Hamdam, H., \& Zaidi, A. M. A. (2009). Assessment of recycled aggregate concrete. Modern Applied Science, 3(10), 47-54.

[15] Sironiya, S., Jamle, S., \& Verma, M. P. (2017). Experimental Investigation On Fly Ash \& Glass Powder As Partial Replacement Of Cement For M-25 Grade Concrete.

[16] Alengaram, U. J., Salam, A., Jumaat, M. Z., Jaafar, F. F., \& Saad, H. B. (2011). Properties of high-workability concrete with recycled concrete aggregate. Materials Research, 14, 248-255.

[17] Arulrajah, A., Piratheepan, J., Ali, M. M. Y., \& Bo, M. W. (2012). Geotechnical properties of recycled concrete aggregate in pavement sub-base applications. Geotechnical Testing Journal, 35(5), 743-751.

[18] Sonawane, T. R., \& Pimplikar, S. S. (2013). Use of recycled aggregate concrete. IOSR Journal of Mechanical and Civil Engineering, 52, 59.

[19] Reddya, C. S., \& Kumara, P. R. Recycling Of Construction And Demolition Waste For Sustainability-An Overview Of The Use Of Recycled Concrete Aggregates.

[20] Husain, A., \& Assas, M. M. (2013). Utilization of demolished concrete waste for new construction. World Academy of Science, Engineering and Technology, 73(2013), 605-610.

[21] Jindal, A., Ransinchung, G. D., \& Kumar, P. Recycled concrete aggregates for rigid pavements: a review.

[22] SEID, N. M. (2019). Experimental investigation on suitability of recycled aggregate in concrete.

[23] Pruthviraj, S. R., Kumar, R., Yajnodbhavi, H. M., Maruthi, 
T., \& Raghavendra, S. (2021). Compressive and Flexural Strength Property Enhancement for Fibre Reinforced M30, M50 and M80 Grade Concrete Using Foundry Sand (FS) and Crushed Concrete Waste (CCW). Journal of Construction Research, 2(2).

[24] Biswal, S., Pandya, T., \& Juremalani, D. J. (2021) Feasibility Study of Construction and Demolition Waste Use in DBM Layer of Flexible Pavement. Elementary Education Online, 20(4), 2175-2181.

[25] Amani, K., Rao, P. N., \& Kumar, V. R. International Journal Of Engineering Sciences \& Research Technology Experimental Study On "M25 Grade Recycled Aggregate Concrete With Addition Of Nano-Silica".

[26] Busari, A., Adeyanju, E., Loto, T., \& Ademola, D. (2019, December). Recycled aggregate in pavement construction: review of literatures. In Journal of Physics: Conference Series (Vol. 1378, No. 2, p. 022026). IOP Publishing.
[27] Mroueh, U. M., Eskola, P., \& Laine-Ylijoki, J. (2001). Lifecycle impacts of the use of industrial by-products in road and earth construction. Waste management, 21(3), 271-277.

[28] Singh, M., Adhikari, A., Maurya, M. K., Srivastava, A., \& Chhabra, R. S. (2020). Feasibility study on use of washedreclaimed asphalt as a partial replacement of natural aggregate in dry-lean concrete as base course for rigid pavement. Journal of Materials in Civil Engineering, 32(9), 04020266.

[29] Nwakaire, C. M., Yap, S. P., Onn, C. C., Yuen, C. W., \& Ibrahim, H. A. (2020). Utilisation of recycled concrete aggregates for sustainable highway pavement applications; a review. Construction and Building Materials, 235, 117444 . 